\title{
The Strategy Research of Modern Service Industry Development
}

\author{
Shumei Wang \\ School of Economics, Wuhan University of Technology, Wuhan 430070, Hubei \\ $\&$ \\ International Business School, Shenyang University, Shenyang 110044, Liaoning, China \\ E-mail: swang1557@yahoo.com.cn \\ Huiyuan Mao (Corresponding author) \\ School of Tourism Administration, Shenyang University, Shenyang 110044, Liaoning, China \\ E-mail: maohuiyuan2004@126.com
}

Received: November 16, $2011 \quad$ Accepted: December 12, $2011 \quad$ Published: February 1, 2012
$\begin{aligned} & \text { doi:10.5539/ass.v8n2p185 } \\ & \text { URL: http://dx.doi.org/10.5539/ass.v8n2p185 }\end{aligned}$

\begin{abstract}
Accelerating the development of modern service industry has become the focus of our national development strategy. The international economic situation has been re-adjusted after the financial crisis. "Green economy" with the core of "clean energy" will turn into a highlight of any nation's reviving in the economy and also of the globe's economic recovery. Take advantage of the opportunity, modern service industry has gone anew on its aggregation and upgrade. It provided us a hard-won opportunity during the Post-crisis period. This paper discussed the strategy of Chinese modern service industry development by analyzing our country's development status and existent conditionality in Chinese modern service industry after the economic crisis.
\end{abstract}

Keywords: Post-crisis period, Modern service industry, Strategy

The modern service industry appears going with the development of information technology and knowledge economy. It takes advantages of new technologies, new types of operation and new service approaches to transform traditional service industry, to create demand, to conduct consumption and to provide production services of high value-added, high level and knowledge-based for the society. Currently, the increase value of global modern service industry occupies over $60 \%$ of total yield value, major developed countries share over $70 \%$, even if the moderate and low-income countries reach the average level of $45 \%$. Industrial structure has been transformed from "industrial-based economy" to "service-based economy," The development level of the modern service industry is the important mark which weighs the developed degree of the modern society economy. For China, how to seize the strategic opportunity to develop modern services industry during "Post-crisis" period, for transforming our mode of rising economy, for realizing our industry transforming to high up value chain, for enhancing ability of innovation of science and technology, for building Innovative country, has strategic significance. It will alter Chinese economic growth pattern and press the industry achieving to value chain's high-end, it will also improve technological innovation and build innovation-oriented country.

\section{The meaning and the basic conditions of emergence of modern service industry}

The wording "modern service industry" was pointed at the report of the political report to the XV congress of CCP in September 1997. The Fifth Session of the Fifteenth Central Committee of the CPC which was about the "fifteen" plan proposal stated that we need to restructure and reform traditional service industry and develop modern service meanwhile. Generally speaking, Compared to traditional service industry, modern service is a kind of inherit, improvement and innovation of traditional service. Presently, the frequently used definition of modern service industry is that the modern service industry appears going with the development of information technology and knowledge economy, it takes advantages of new technologies, new types of operation and new service approaches to transform traditional service industry, to create demand, to conduct consumption and to provide production services of high value-added, high level and knowledge-based for the society. Generally speaking, the modern service industry developed into newly risen service industry and "renewed vigor" 
traditional service industry with being transformed partially, through depending on information technology and modern ideas during industrial products entering the mass consumption stage. Compared with the traditional service industry, modern service industry is the embodiment of the new economy. It possesses some competitive advantages of informatization, internationalization, scale and brand, and has also some industrial characteristics, such as high growth, high increase, high tech knowledge content and strong radiation. It plays important role of optimizing the industrial structure and improving the industrial competitiveness and competitiveness of cities.

The basic conditions depended on by the cosmically developed modern service industry comprise of (1) Trend of service presented by the increasing enhancement of the level of economic development and high development of manufacturing brings service activities generalization, and even into the service economy era; (2) the constant growth of social specialization associated with the improvement of the degree of Marketization changes internal service into external service, and brings service independent. (3) the application of modern information technology has altered some nature of service activities and has promoted service activities development of generalization and independence. On the base of that, the paper analyzed present basic conditions of Chinese modern service industrial development. As a conclusion, service supply rigidity caused by insufficient competition and low marketization degree is the main reason of weak modern service industrial development. That includes controls in terms of industry monopoly, barriers to entry, price and so on, and system obstacle such as disordered market etc.

\section{Restricting factors of modern service industrial development}

At present, with Chinese economic development, modern service industry has been rapidly developing, Its GDP has been kept steady growth. Modern service industry has become one of the main drivers of Chinese economic growth. However, modern service industrial development is facing some problems. Firstly, technical content needs to be improved. Overall technical content of Chinese service industry is not high, labor productivity is low, The percentage that technology contributes to service industry also needs to be enhanced. Secondly, the innovation ability is about to be strengthened. Weak innovation ability restricts modern service development. Thirdly, the financing difficulties need to be improved urgently. Most service enterprises hardly obtain loans from banks due to small scale, low credit and lack of sufficient guarantees etc. Fourthly, the problem of talent shortage has revealed. Although there are abundant human resources in China, shortage of service talent, especially structural shortage has always constrained the development of China's modern service industry. Last but not the least, there exists regional imbalances in the development of Chinese service industry. The modern service industry is gathering to large cities, which shows a cluster of trend. There are two main constrain factors that result in these problems.

\subsection{The overall level of our modern service industry development is not high.}

According to the global economic development, the percentage of modern service industry in the entire national economy tends to rise. Although the modern service industry has developed over a few decades, the overall development level is still not high. Chinese modern service industry shares around 40\% of GDP. However the world average level has already reached $67 \%$, developed countries generally attained over $71 \%$, whereas developing countries' average is about $45 \%$. The percentage in china is not only lower than developed countries but also lower than the average of developing countries. The proportion of Chinese employed labor force of modern service industry in entire employed labor force is far lower than that of most developing countries. It is $32.36 \%$ in the end of 2007 , which is $70 \%-80 \%$, lower than developed countries and is also even $50 \%$ lower than developing countries. Most of Chinese labor force distribute in the first and second industry and the basis sector of tertiary industry. There is a small proportion of people employed in High skilled sector, which is difficult to solve the employment of graduated students. The majority of people in china are rural population and the ability of modern service industries absorbing labor force is not strong. It will be hard to achieve the transfer of the employment of Chinese rural population, to solve the three agricultural problems, to alleviate the current employment pressure China is presently facing.

2.2 The modern service system of our country is flawed, showing that modern service market opens inadequately, the competitiveness is insufficient and lack of industrialization, field of consumer services is narrow

This is mainly due to institutional flawed system. For a long time, owing to Chinese economic development situation that takes first and second industry as main body, the idea of Non-industrial management of development of modern service industry, tight government control and even nationalization of most services industry, weak profitability, it has presented the states of integration of government administration with enterprise and irrespective of government affairs and of nonprofit entities and profitable institutions. Many ranges of services have still been deemed as unproductive activities so far. Moreover, many fields of services 
which are still being treated as public welfare can be operated commercially. As a result low capacity and economic effectiveness is unable to form the industrial superiority, which restricts the modern service industry development. Some service industries (such as postal services, telecommunications, finance) have been set up the insurmountable barrier to entry, which makes it difficult for non-public economy to enter. This will firstly cause lack of competition in these industries, resources cannot flow freely in these areas and rigid managerial mechanism; Secondly, it will also make these enterprises within these industries too dependent on government investment, lack of self-development mechanism, and form oligopolistic market, result in the modern service industry market failure, however, the government not only failed to solve the failure to play the role of macro-control, but also interfered with the normal development of China's modern service industry, thereby seriously hampered the optimization of industrial structure of China's modern service and productivity improvement. Above factors make the development of China's modern service industry possess many constraints that lead our modern service industry developed inefficiently.

\section{The strategies of modern service industry development in "post-crisis" period}

The international economic situation has been re-adjusted after the financial crisis. The new industry aggregation and enhancement triggered by modern service industry will become highlights of revitalizing the economy and of the global economic recovery, which provides a rare opportunity to China. However, because of its inherent limitations, the liberation and development of our country's modern service industry need to be further accelerated.

\subsection{Improve the technological content of the modern service industry and innovative level}

Currently, the productive service industry has become the main part of modern service industry. Due to full use of modern scientific and technological achievements, it not just has had high technological content, but also guided the trends in the world in aspect of technology, management and operation. The financial crisis promoted transformation of the way of economy growth and accelerated the industrial shift from east our country to mid-west. It has not only provided conditions for productive service industry development, bust also raised requirements to increasing their technological contents and innovation abilities. So it will be great if we can take advantages of favorable opportunity offered by the financial crisis to strive to develop productive service industries of high technological contents and innovation abilities in terms of research and development, of cultural originality, of supply chain management etc, by taking effective measures.

\subsection{Promote the overall quality of the modern service industry}

Radically, the competition of modern service industry is competition of talent. The level of development ultimately depends on the human quality and employment mechanism. For now, Most of our service employees are still concentrated in traditional ranges of services. The talents who meet the needs of modern service industry are lacking. There are less people with technical expertise in service sectors jobholders. Particularly, the good management talents engaging in modern logistics industries, exhibition industries, finance services, community services, intermediary services, information services and other aspects are even lacking relatively. Moreover the irregular personnel quality, behindhand management ideas, low-rise service efficiency and value added per capita seriously constrain the development of modern service industry in China. In view of above status quo, what we need to do are that focus of fostering and absorbing talents should be shifted to modern logistics, finance, insurance, electronic commerce, information services and other high-tech fields, moreover, increase the human capital investment to mid-west areas and encourage the Eastern talents to flow there, and then promote the balanced development of service industry.

\subsection{Accelerate the formation of financing modes suitable for the development of modern service industry}

Cultural and creative industries have characteristics of counter-economic cycle and buck the trend and can develop into important pillar industry. In a view of global experiences, economic crisis period is the golden age of cultural industries' prosperity. United States, Japan, South Korea's development of cultural and creative industries have proven this point. There are some recommendations to accelerate the development of Chinese Cultural and creative industries. Firstly, government should fully play the active role of to solve the problem of financing difficulties by setting up cultural and creative industrial fund. Secondly, fight the clock to study and solve problems existing in the intellectual property pledge loan and form the mature loan modes as soon as possible. Thirdly, positively develop professional guarantee companies aiming at modern service industry in order to reduce the risk of banks and lending initiatives. On this basis, form financing modes suitable for the development of modern service industry. 


\subsection{Promote the scale and the brand of Chinese modern service industry}

At present, in order to make the best of the opportune time provided by financial crisis to expand the scale of Chinese modern service industry, firstly, we should encourage and support mergers of taking market as centre and taking ownership as bases between the modern service enterprises, especially service outsourcing enterprises, cultural and creative enterprises and software services enterprises. Moreover, particularly encourage international mergers and acquisitions for forming quickly a large number of modern service industries with international competitive and over 30 thousand. Secondly, encourage modern service enterprises to exploit international customer resources, and also, encourage qualified and competent enterprises to go abroad and set up Order Company and service agencies etc. Thirdly, further perfect the soft hardware environments of modern service industry, including inland service businesses kept out to overseas companies, strict foreign exchange control etc. Lastly, unveil fresh policies regarding taxes, charges, information secrecy and qualification accreditation as fast as can to encourage domestic government, organization and enterprises to outsource non-core business, and provide added business resources for modern service companies.

\section{References}

Bi, Dezhi, etc. (2006). The research of China's modern service industry development strategy. Reforms and strategies, (1).

Feng, Hua \& Si Guanglu. (2008). The development of modern service industry trends and policy recommendations with the new economic conditions. Macro-economic research, (5).

Li, Jingwen. (2008). Transformation of economic development, vigorously develop modern services. Economic Research Reference, (9).

Wang, Yao \& Zhang, Yang. (2009). The newest development research of the domestic service industry. Finance Theory and Practice, (1).

Xia, Mingshou. (2008). The central region of modern service industry development status and path selection. Business Times, (34). 